\title{
Association of plasma endothelial lipase levels on cognitive impairment
}

\author{
Sang-Moon Yun ${ }^{1 *}$, Jee-Yun Park', Sang Won $\mathrm{Seo}^{2}$ and Jihyun Song ${ }^{1}$
}

\begin{abstract}
Background: Peripheral high-density lipoprotein cholesterol (HDL-C) has been known to influx into the brain and be inversely associated with the risk of Alzheimer's disease (AD). However, recent prospective studies of the association between HDL-C and AD have yielded inconsistent results. Here, we examined the association between the endothelial lipase (EL), which is known to be major determinant of HDL-C levels, and cognitive function.

Method: We compared plasma from 20 patients with Alzheimer's disease (AD), 38 persons with mild cognitive impairment, and 51 cognitively normal controls. Plasma EL levels were measured using the enzyme-linked immunosorbent assay.

Results: EL levels were inversely correlated with $\mathrm{HDL}-\mathrm{C}$, as previously reported; however, there were no mean differences in plasma EL between the diagnostic groups. An analysis by classification of dementia severity according to clinical dementia rating (CDR) showed that the EL levels were significantly higher in the CDR1 group (mild dementia), as compared to CDRO (no dementia), CDR0.5 (very mild), and CDR2 (moderate) groups. Prior to moderate dementia stage, trends analysis showed that EL levels tended to increase with increasing severity ( $p$ for trend $=0.013$ ). Consistently, elevated EL levels were significantly correlated with the mini-mental state examination (MMSE) score $(r=-0.29, p=0.003)$. Logistic regression for association between plasma EL and cognitive impairment (MMSE score $\leq 25)$ showed that participants with EL levels in the upper range $(>31.6 \mathrm{ng} / \mathrm{ml})$ have a higher adjusted odds ratio of cognitive impairment than those within the lower EL range.
\end{abstract}

Conclusion: Findings from the present study reflect the association of EL and cognition, suggesting that the individuals with elevated plasma EL concentration are at an increased risk of cognitive impairment.

Keywords: Alzheimer's diseases (AD), Endothelial lipase (EL), Clinical dementia rating (CDR), Cognitive impairment, High density lipoprotein cholesterol (HDL-C)

\section{Background}

Lipid metabolism has a potential role in the development and progress of Alzheimer's disease (AD). Abnormal lipid in the brain has been considered as a histological feature of $\mathrm{AD}$ [1]. The Apolipoprotein $\mathrm{E}$ (ApoE) gene is known to play a role in neuronal lipid homeostasis in the brain, and ApoE genotype has been associated with an increased risk of AD [2]. Genomewide association studies have shown that lipid metabolism and transport are one of the main pathways involved in the pathological process of $\mathrm{AD}[3,4]$.

\footnotetext{
* Correspondence: ysm0304.0304@gmail.com

${ }^{1}$ Division of Brain Diseases, Center for Biomedical Sciences, Korea National Institute of Health, Cheongju-si, Chungcheongbuk-do 28159, Republic of Korea

Full list of author information is available at the end of the article
}

Furthermore, autopsy studies have shown that an abnormal lipid profile in peripheral blood precedes the pathological characteristics of $\mathrm{AD}$ [5-7]. A recent meta-analysis of cohort studies found that increased cholesterol in mid-life, not in late-life, is associated with incident dementia in old age [8]. This current evidence supports an involvement of dyslipidemia in development of AD.

Recent prospective studies with moderate to large sample sizes have suggested that high- density lipoprotein cholesterol (HDL-C), one of the blood lipid parameters, may be inversely associated with the risk of AD [9-11]. However, the relatively small epidemiological studies that have subsequently investigated the association between serum HDL-C and AD risk have yielded inconsistent

(c) The Author(s). 2019 Open Access This article is distributed under the terms of the Creative Commons Attribution 4.0 International License (http://creativecommons.org/licenses/by/4.0/), which permits unrestricted use, distribution, and reproduction in any medium, provided you give appropriate credit to the original author(s) and the source, provide a link to the Creative Commons license, and indicate if changes were made. The Creative Commons Public Domain Dedication waiver (http://creativecommons.org/publicdomain/zero/1.0/) applies to the data made available in this article, unless otherwise stated. 
results [12, 13]. Inconsistent findings for a link between HDL-C and AD risk may come from misclassification of dementia resulting from varying diagnostic criteria [11] and insufficient follow-up times to show the effect of HDL-C on incident AD [8]. In addition, HDL-C measurement is relatively less standardized and less precision, compared with total cholesterol (TC) [14]. Because clinically meaningful differences in concentrations are small, the HDL-C measurement error might contribute to these conflicting results [15].

The endothelial lipase (EL, also alternatively named LIPG) plays an important role in HDL metabolism. EL hydrolyzes HDL phospholipids and clears HDL-C from the circulation $[16,17]$. Gain and loss of function studies in mice have indicated that EL is major determinant of HDL-C [18-20]. Genetic variation studies have supported a positive correlation between EL and blood HDL-C in humans [21, 22]. EL does not affect other lipid-related blood parameters [23]. EL is secreted by vascular endothelial cells, medial smooth muscle, and macrophages on atherosclerotic lesions [24]. Induced inflammation in endothelial cells treated with TNF- $\alpha$ or interleukin-1 $\beta$ as well as in mice on LPS administration results in elevation levels of EL mRNA and protein [25-27]. These results suggest that EL expression is regulated by inflammatory stimuli.

So far, evidence for the role of HDL-C on cognitive decline and dementia, and that for the role of EL on determining of HDL-C has been separately accumulated; the link between EL and cognition has not yet been studied. Thus, in the current study, we examined whether the blood EL concentrations were associated with cognitive impairment in a cross-sectional study of elderly people in Korea.

\section{Methods}

\section{Subjects}

We recruited 97 participants including cognitively normal individuals $(N=39)$, amnestic MCI $(N=38)$, and AD-type dementia $(N=20)$ from the memory clinic in Samsung Medical Center, from February 2017 to August 2017. Additionally, we recruited 29 cognitively normal participants from the local community. Five participants were excluded due to the withdrawal of consent, and a participant was excluded due to the failure of obtaining an amyloid PET scan. Of the remaining 120 participants, 11 subjects with a coefficient of variation of $30 \%$ or more in the EL measurements were excluded. A total of 109 elderly participants (mean age; 75.3 years) over 65 years of age were recruited from a clinic and local community (Additional file 1: Figure S1). The subjects consisted of 51 cognitively normal controls (NC), 38 patients with amnestic mild cognitive impairment (aMCI), and 20 patients with AD. All participants underwent neurological examination, neuropsychological (NP) testing, and routine blood tests. Blood tests for all participants included a complete blood count, blood chemistry tests, vitamin B12/folate, syphilis serology, thyroid function tests and APOE genotyping. Participants with current or past neurological or psychiatric illnesses such as major depressive disorders, epilepsy, brain tumors, encephalitis or severe head trauma that would affect cognitive function were excluded. On MRI, patients with structural lesions such as tumors, traumatic brain injuries, or hydrocephalus were also excluded. The institutional review boards approved this study. Written, informed consent was obtained from patients and caregivers.

The NC was volunteered community based elderly who had no history of neurological or psychiatric illness, and had no abnormalities upon neurological examination. The NC exhibited normal cognition on the detailed neuropsychological tests. Patients met the following criteria for aMCI proposed by Petersen et al. [28]: (1) subjective memory complaints by the patient or an informant; (2) relatively normal performance in other cognitive domains; (3) normal activities of daily living (ADL), as judged clinically; (4) objective memory decline below - 1.0 SD on either verbal or visual memory tests; and (5) not demented. AD was diagnosed based on National Institute on Aging-Alzheimer's Association (NIAAA) research criteria for probable AD [29].

\section{Neuropsychological tests}

All participants underwent a standardized neuropsychological battery called the Seoul Neuropsychological Screening Battery, which consisted of tests of attention, language, visuospatial, memory, and frontal/executive functions [30]. Tests that were scored included the following: The Korean version of the Boston Naming Test (KBNT), Rey-Osterrieth Complex Figure Test (RCFT: copying, immediate and 20-min delayed recall, and recognition), Seoul Verbal Learning Test (SVLT: immediate, 20min delayed recall and recognition), phonemic and semantic Controlled Oral Word Association Test (COWAT) and the Stroop Test (word and color reading). SVLT and RCFT were performed to assess verbal and nonverbal learning and memory. The K-BNT and RCFT copy were done to evaluate language and visuospatial function, respectively. Phonemic and semantic COWAT and the Stroop Test were performed to evaluate frontal/ executive function. Scores were considered abnormal when they were lower than - 1.0 SD below age- and education-adjusted norms. All participants also were administered the Clinical Dementia Rating Scale Sum of Boxes (CDR-SOB). Clinical Dementia Rating (CDR) on 5point scale was scored using the CDR-SOB. The Korean version of the Mini-Mental Status Examination (K- 
MMSE, range 0 to 30) was also administered. Tests were administered by experienced staff and supervised by board-certified clinical neuropsychologists.

\section{Amyloid PET data acquisition and positivity}

Patients underwent florbetaben (FBB) PET or flutemetamol (FMM) PET at Samsung Medical Center using a Discovery STe PET/CT scanner (GE Medical Systems, Milwaukee, WI, USA) in three-dimensional scanning mode. ${ }^{18} \mathrm{~F}$-florbetaben PET was classified as positive when visual assessment was scored as 2 or 3 on brain amyloid-plaque load (BAPL) scoring system [31, 32]. Visual interpretation of ${ }^{18} \mathrm{~F}$-flutemetamol PET images relied upon a systematic review of five brain regions (frontal, parietal, posterior cingulate and precuneus, striatum and lateral temporal lobes) [33]. More detailed procedures are described in supplementary methods section (Additional file 1: Methods).

\section{Measurement of plasma EL}

The plasma concentrations of EL were measured using the ELISA kit (Cloud-Clone Corp., Houston, TX; SEA469Hu) according to the manufacture's protocol. Plasma sample was separated with EDTA as anticoagulant. EL release is induced by administration of heparin, but EL levels in pre heparin condition are significantly correlated with levels of post heparin condition [34]. To assess the correlation between plasma EL mass and cognitive impairment, therefore, EDTA-plasma was obtained without administration of heparin. Each level is mean values of the duplicate measurement.

\section{Statistical analysis}

Group differences were calculated using either t-tests or an analysis of variance (ANOVA) followed by post hoc tests for continuous variables and chi-square tests for nominal variables. Linear trend was estimated using the ANOVA results and with a polynomial contrast. Pearson correlation coefficients were used to quantify associations between variables. Simple and multiple logistic regression analyses were conducted to calculate odds ratios (ORs) of cognitive impairment (MMSE score $\leq 25)$ per 1 standard deviation (SD) increment of plasma EL concentration. The MMSE cutoff chosen for the general cognition function varied from 23 to 26 [35]. We determined MMSE score $\leq 25$ as cognitive impairment. All calculations, graphs and statistical analyses were performed using SPSS ver. 19.0 (IBM Corporation, Armonk, NY) and GraphPad Prism 5 (GraphPad Inc., La Jolla, CA).

\section{Results}

\section{Demographic and clinical data}

Demographic and clinical data are shown in Table 1 . The mean age of patients with $\mathrm{AD}$ was 79.1 years old, which was significantly older than the cognitively normal

Table 1 Participant demographics, clinical data, blood tests, and EL concentration according to diagnosis

\begin{tabular}{|c|c|c|c|c|c|}
\hline & Total & control & $\mathrm{MCl}$ & $A D$ & $P$-value \\
\hline N & 109 & 51 & 38 & 20 & \\
\hline Age & $75.3 \pm 5.7$ & $73.8 \pm 4.9$ & $75.3 \pm 5.0$ & $79.1 \pm 7.2$ & 0.002 \\
\hline Sex, male/female N (female \%) & $37 / 72(66 \%)$ & $10 / 41(80 \%)$ & 19/19 (50\%) & $8 / 12(60 \%)$ & $0.009^{*}$ \\
\hline Education, years & $9.8 \pm 4.7$ & $9.4 \pm 5.2$ & $10.6 \pm 3.9$ & $9.2 \pm 4.9$ & 0.413 \\
\hline BMl & $24.0 \pm 2.7$ & $24.2 \pm 2.6$ & $23.8 \pm 2.7$ & $24.0 \pm 2.9$ & 0.829 \\
\hline Total Protein (g/dL) & $7.0 \pm 0.5$ & $7.1 \pm 0.5$ & $7.0 \pm 0.4$ & $6.8 \pm 0.5$ & 0.046 \\
\hline Albumin (g/dL) & $4.3 \pm 0.3$ & $4.4 \pm 0.3$ & $4.4 \pm 0.3$ & $4.2 \pm 0.3$ & 0.010 \\
\hline Total Cholesterol (mg/dL) & $177.0 \pm 32.0$ & $174.1 \pm 30.2$ & $175.8 \pm 31.4$ & $186.8 \pm 37.3$ & 0.312 \\
\hline $\mathrm{HDL}-\mathrm{C}(\mathrm{mg} / \mathrm{dL})$ & $54.0 \pm 16.5$ & $56.9 \pm 16.7$ & $53.2 \pm 16.4$ & $50.1 \pm 16.4$ & 0.365 \\
\hline LDL-C (mg/dL) & $108.9 \pm 30.0$ & $104.9 \pm 30.2$ & $109.3 \pm 28.6$ & $118.2 \pm 31.3$ & 0.246 \\
\hline Triglyceride (mg/dL) & $149.3 \pm 84.6$ & $138.5 \pm 62.4$ & $152.0 \pm 95.8$ & $171.4 \pm 108.2$ & 0.330 \\
\hline ApoE4 carrier, N (\%) & $36(33 \%)$ & $11(22 \%)$ & $14(37 \%)$ & $11(55 \%)$ & $0.022^{*}$ \\
\hline Amyloid PET positive N (\%) & $40(37 \%)$ & $9(18 \%)$ & $18(47 \%)$ & $13(65 \%)$ & $<0.001^{*}$ \\
\hline CDR & $0.6 \pm 0.5$ & $0.4 \pm 0.2$ & $0.5 \pm 0.1$ & $1.5 \pm 0.8$ & $<0.001^{*}$ \\
\hline CDR-SOB & $2.4 \pm 3.7$ & $0.7 \pm 0.4$ & $1.5 \pm 1.1$ & $8.8 \pm 4.7$ & $<0.001$ \\
\hline MMSE & $25.0 \pm 5.3$ & $27.6 \pm 2.1$ & $25.9 \pm 2.7$ & $16.6 \pm 6.4$ & $<0.001$ \\
\hline $\mathrm{EL}(\mathrm{ng} / \mathrm{ml})$ & $21.4 \pm 10.1$ & $21.0 \pm 8.8$ & $21.9 \pm 9.7$ & $21.7 \pm 14.2$ & 0.899 \\
\hline
\end{tabular}

The continuous value is represented by mean \pm SD

$p$-values are for the analysis of variance (ANOVA), * for chi-squared test of independence

Abbreviation: $B M I$ body mass index, $H D L-C$ high density lipoprotein cholesterol, $L D L-C$ low-density lipoprotein cholesterol, ApoE, Apolipoprotein $\mathrm{E}_{;} \mathrm{CDR}$, clinical dementia rating; CDR-SOB, clinical dementia rating scale sum of boxes, MMSE mini-mental state examination, EL endothelial lipase 
control (NC) group (73.8 years old, $p<0.001$ ) and $\mathrm{MCI}$ group (75.3 years old, $p<0.05$ ). There was no betweengroup difference in the number of years of education, body mass index (BMI) score or lipid parameters, such as TC, HDL-C, low-density lipoprotein cholesterol (LDL-C) and triglyceride (TG). But between-group difference in sex ratios, total protein or albumin was observed. ApoE4 allele carriers in the $\mathrm{AD}$ group comprised $55 \%$, which was significantly more frequent than those in the $\mathrm{NC}(22 \%)$ and $\mathrm{MCI}$ (37\%) groups. Positive Amyloid PET brain scans were found in $18 \%$ of the control group, $47 \%$ of the MCI group and $65 \%$ of the $\mathrm{AD}$ group. The average MMSE score of the MCI group $(25.9 \pm 2.7)$ was lower than control group $(27.6 \pm 2.1 ; p<0.05)$, and the average MMSE score of the $\mathrm{AD}$ group (16.6 \pm 6.4$)$ was lower than both other groups (both $p<0.001)$. Clinical dementia rating (CDR) scores were higher in $\mathrm{AD}$ group compared to both other groups (both, $p<0.001$ ). However, the difference in CDR score between $\mathrm{NC}$ and $\mathrm{MCI}$ groups was not observed.
Relationships of EL with cognitive impairment

Plasma EL showed no significant between-diagnostic group differences (Table 1). EL was inversely correlated with HDL-C $(\mathrm{r}=-0.24, p=0.015)$ in the blood lipid profile, and was not correlated with TC, LDL-C, or triglyceride (Additional file 1: Figure S2). Additionally, plasma EL was positively correlated with white blood cell (WBC) and platelet counts. (Additional file 1: Table S1).

The analysis by classification of dementia severity according to CDR scores, showed that there were significant group differences between CDR groups (Fig. 1; oneway ANOVA; $p=0.03$ ). The EL levels were significantly higher in the CDR 1 group $(30.5 \pm 5.1)$ than in the CDR $0(19.4 \pm 1.9, p=0.012)$, CDR $0.5(21.4 \pm 1.1, p=0.01)$ or CDR $2(15.5 \pm 3.9, p=0.003)$ groups (Fig. 1). There was no trend of EL concentration in the whole CDR severity range. However, as the severity of dementia increased from $\mathrm{CDR}=0$ to $\mathrm{CDR}=1$, the $\mathrm{EL}$ concentration tended to increase ( $p$ for trend $=0.013$; Fig. 1 ) and elevated EL

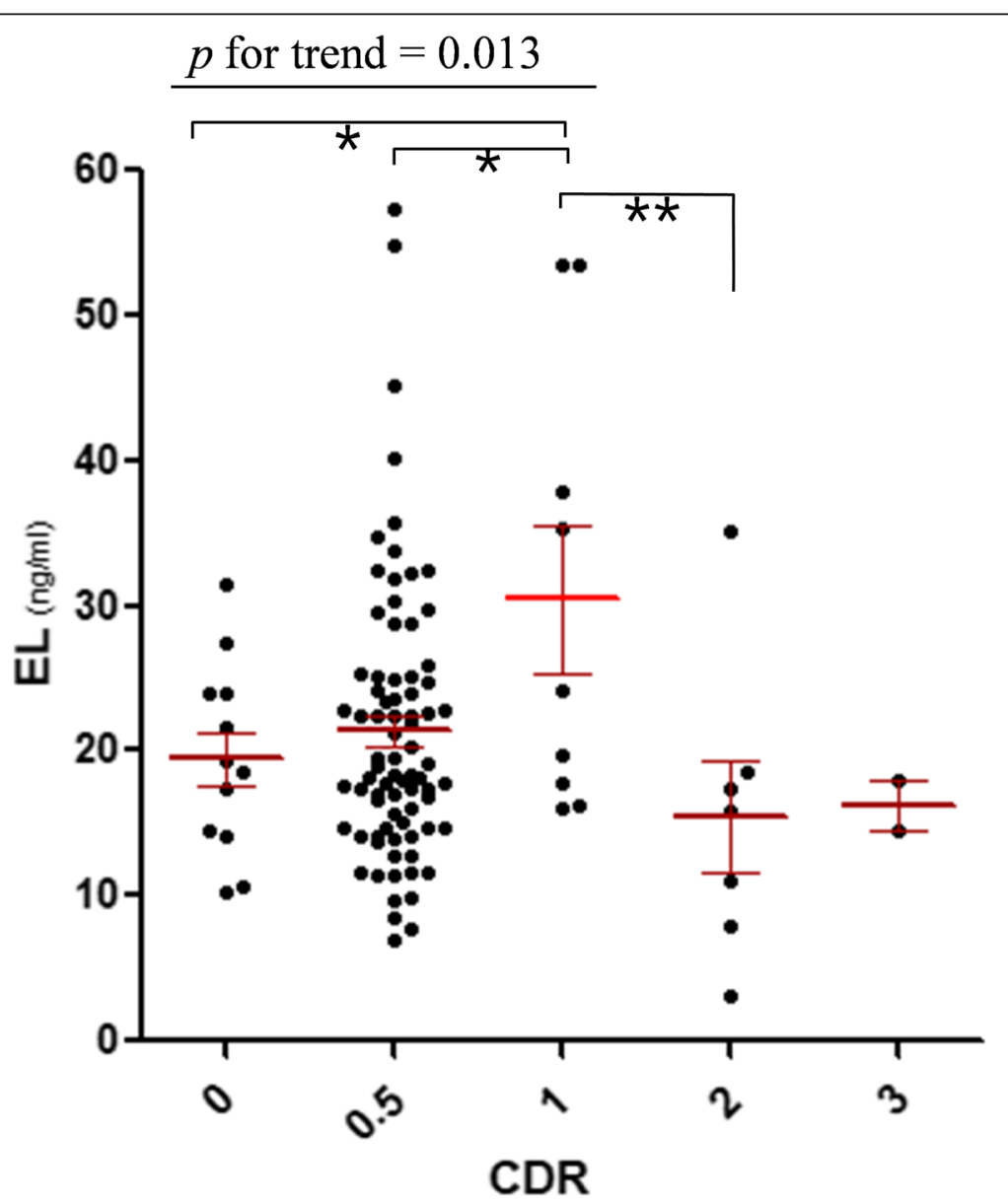

Fig. 1 Plasma EL levels according to CDR scores. The grouped Scatter plot shows plasma EL concentrations across CDR scores. Each level is mean values of the duplicate measurement, below the coefficient of variation $<30 \%$. Red bars represent mean \pm S.E.M of each CDR group. Comparisons were made using a One-way ANOVA, followed by post-hoc analysis with the Least Significant Difference test. Significance is indicated with * and ** representing $p<0.05$ and $p<0.01$ respectively. The linear trend was analyzed from CDR0 to CDR1. Abbreviations: CDR, clinical dementia rating; $E L$, endothelial lipase 
levels were significantly correlated with MMSE score $(\mathrm{r}=-0.29, p=0.003$; Additional file 1: Figure S3). However, the elevated levels of plasma EL were not correlated with the presence of ApoE4 $(p=0.265)$ or amyloid deposit in the brain (t-test $p=0.199$ ) (Additional file 1: Figure S4).

To determine the association between EL and cognitive impairment (MMSE score $\leq 25)$, we investigated ORs in subjects from cognitively normal to mild dementia (Table 2 and Table 3). EL concentration was categorized into two ranges according to the mean +1 standard deviation $(31.6 \mathrm{ng} / \mathrm{ml})$. Participants that fell into the upper range of EL had a higher unadjusted OR of cognitive impairment $(\mathrm{OR}=5.4,95 \%$ confidence interval $[\mathrm{CI}], 1.7-17.5)$ than those that fell into lower range. When adjusted for age, sex, education, BMI, ApoE e4 allele and Amyloid-PET imaging, and additionally adjusted for disease history including diabetes hyperlipidemia, heart disease, hypertension, stoke, traumatic brain injury, the ORs of cognitive impairment in the upper range group compared with the lower range group were similar to those of the unadjusted model $(\mathrm{OR}=4.8,95 \% \mathrm{CI}$ 1.3-17.9; OR $=5.6,95 \%$ CI 1.4-22.9, respectively).

\section{Discussion}

In the present study, we demonstrated that plasma EL concentration was associated with cognitive impairment in a sample of elderly Korean people. First, we assessed that there was no mean difference in EL levels between diagnostic groups of dementia, MCI and NC. Secondly, we used CDR, which represent dementia severity, to compare the differences in EL levels between the degree of cognitive impairment. Levels of plasma EL were significantly higher in the CDR1 group compared to both

Table 2 Participant demographics, clinical data, blood tests, and history of disease according to plasma EL concentration prior to moderate dementia stage

\begin{tabular}{|c|c|c|c|c|}
\hline & \multicolumn{4}{|c|}{ Categorization into the mean + 1 SD of plasma EL concentration } \\
\hline & Lower range of EL & Upper range of EL & Total & $p$-value \\
\hline & $<31.6 \mathrm{ng} / \mathrm{ml}, n=85$ & $\geq 31.6 \mathrm{ng} / \mathrm{ml}, n=15$ & $n=100$ & \\
\hline$\overline{E L}(\mathrm{ng} / \mathrm{ml})$ & $18.6 \pm 5.6$ & $40.7 \pm 9.5$ & $22.1 \pm 10.1$ & $<0.001$ \\
\hline Age & $74.5 \pm 5.3$ & $77.9 \pm 5.3$ & $75.0 \pm 5.4$ & 0.025 \\
\hline Sex, male/female N (female \%) & $56(66 \%)$ & $9(60 \%)$ & $65(65 \%)$ & $0.66 *$ \\
\hline Education, years & $9.8 \pm 4.6$ & $9.0 \pm 5.4$ & $9.7 \pm 4.7$ & 0.589 \\
\hline BMI & $24.1 \pm 2.7$ & $23.6 \pm 1.9$ & $24.0 \pm 2.6$ & 0.486 \\
\hline Total Protein (g/dL) & $7.0 \pm 0.5$ & $7.0 \pm 0.5$ & $7.0 \pm 0.5$ & 0.878 \\
\hline Albumin (g/dL) & $4.4 \pm 0.3$ & $4.3 \pm 0.3$ & $4.4 \pm 0.3$ & 0.635 \\
\hline ApoE4 carrier, N (\%) & $24(28 \%)$ & $6(40 \%)$ & $30(30 \%)$ & $0.359 *$ \\
\hline Amyloid-PET positive N (\%) & $27(32 \%)$ & $6(40 \%)$ & $33(33 \%)$ & $0.532 *$ \\
\hline CDR & $0.5 \pm 0.2$ & $0.6 \pm 0.2$ & $0.5 \pm 0.2$ & $0.006 *$ \\
\hline CDR-SOB & $1.3 \pm 1.4$ & $2.8 \pm 3.0$ & $1.5 \pm 1.8$ & 0.074 \\
\hline MMSE & $26.5 \pm 3.3$ & $22.6 \pm 5.5$ & $25.9 \pm 3.6$ & 0.017 \\
\hline \multicolumn{5}{|l|}{ Diagnosis } \\
\hline Control, N & 47 & 4 & 51 & $0.042 *$ \\
\hline $\mathrm{MCl}, \mathrm{N}$ & 31 & 7 & 38 & \\
\hline$A D, N$ & 7 & 4 & 11 & \\
\hline \multicolumn{5}{|l|}{ Disease history, N(\%) } \\
\hline Diabetes & $12(14 \%)$ & $3(20 \%)$ & $15(15 \%)$ & $0.556 *$ \\
\hline Hypertension & $43(51 \%)$ & $8(53 \%)$ & $51(51 \%)$ & $0.845 *$ \\
\hline Hyperlipidemia & $40(47 \%)$ & $7(47 \%)$ & $47(47 \%)$ & $0.978 *$ \\
\hline Heart disease & $10(12 \%)$ & $2(13 \%)$ & $12(12 \%)$ & $0.863 *$ \\
\hline Stroke & $4(5 \%)$ & $0(0 \%)$ & $4(4 \%)$ & $0.391 *$ \\
\hline Traumatic brain injury & $4(5 \%)$ & $0(0 \%)$ & $4(4 \%)$ & $0.391 *$ \\
\hline
\end{tabular}

The continuous value is represented by mean \pm SD

$p$-values are for the t-test, ${ }^{*}$ for chi-squared test of independence

Abbreviation: $B M I$ body mass index, $A p o E$ Apolipoprotein $E, C D R$ clinical dementia rating, $C D R-S O B$ clinical dementia rating scale sum of boxes, MMSE mini-mental state examination, EL endothelial lipase 
Table 3 ORs for cognitive impairment according to plasma EL concentration prior to moderate dementia stage

\begin{tabular}{llll}
\hline & \multicolumn{2}{c}{ Categorization into the mean + 1 SD of plasma EL concentration } \\
\cline { 2 - 4 } & Lower range of EL & Upper range of EL & $p$ value \\
& $<31.6 \mathrm{ng} / \mathrm{ml}, n=85$ & $21.6 \mathrm{ng} / \mathrm{ml}, n=15$ & 0.005 \\
\hline Not adjusted & 1 (ref.) & $5.4(1.7-17.5)$ & 0.021 \\
Adjusted for covariates $^{\mathrm{a}}$ & 1 (ref.) & $4.8(1.3-17.9)$ & 0.016 \\
Adjusted for covariates $^{\mathrm{b}}$ & 1 (ref.) & $5.6(1.4-22.9)$ & \\
\hline
\end{tabular}

Figures in brackets after each odds ratio indicated $95 \%$ confidence intervals

${ }^{\mathrm{a}}$ Age, sex, education, BMI, APOE-e4 allele, Amyloid PET

${ }^{\mathrm{b}}$ Age, sex, education, BMI, APOE e4 allele, Amyloid PET, history of disease (diabetes, hyperlipidemia, heart disease, hypertension, stroke, traumatic brain injury)

the less severe stages (CDR0 and CDR0.5) and the more severe stage (CDR2). Prior to the CDR2 stage, EL levels had a tendency to increase with increasing severity of dementia. Thirdly, we used the MMSE score to reconfirm the relevance between cognitive impairment and EL. Elevated EL levels were significantly associated with reduction of cognitive function.

This is the first study to determine the association between EL and cognitive function. Elevated EL levels in individuals under CDR1 were significantly correlated with cognitive impairment, as assessed by the MMSE. Moreover, logistic regression analysis of the association between upper EL (>31.6) and cognitive impairment (MMSE score $\leq 25)$ showed that participants with an upper EL range had at a higher risk (adjusted Odds Ratio $=5.6$; $p$-value $=0.016$ ) of cognitive impairment than those with a lower range. Recently, a relevant study investigated the effect of EL common variant on AD [36]. The EL variant carrier suggested showing at a higher risk of AD.

EL facilitates the hydrolysis of HDL phospholipids and clears HDL-C from the circulation [16]. EL is known as a major regulator of HDL-C and does not affect other lipid parameters [20, 21, 23]. High HDL-C has been associated with better memory performance, while low HDL-C has been associated with a decline in memory and cognition [37-39]. Consistent with this work, we observed higher HDL-C levels when there were lower EL levels (Additional file 1: Fig. S2). However, other lipid profiles, such as TC, LDL-C, and triglyceride (TG), were not correlated with EL. Notably, there was a significant difference in EL levels between CDR groups (Fig. 1), but no significant differences in HDL-C levels between CDR groups ( $p=0.85$, Additional file 1: Table S2). These results suggest that EL concentration may better reflect the severity of dementia than HDL-C levels.

Inflammation which is a necessary and adaptive defense response to different harmful stimuli has been linked to dementia [40-42]. Systemic and chronic inflammation in which immune system is over-activated, can lead to an attack on healthy brain cells and the subsequent progression to dementia [43, 44]. Infectious pathogens, such as fungus [45, 46], bacteria [47], viruses [48] can directly and indirectly induce neuro-inflammation, leading to $\mathrm{AD}$ pathology [49]. Consistent with these findings, we observed that EL was correlated with peripheral platelet and white blood cell counts, which are blood inflammatory markers $[50,51]$. These results are consistent with evidence that EL levels are positively correlated with other inflammatory markers, C-reactive protein and interleukin 6 [52-54], and that its mRNA and protein levels are regulated by cytokine and LPS [25-27].

We found that EL levels tended to increase with dementia severity prior to the CDR2 stage, but decreased at CDR2 and CDR3 stages. This pattern, which shows the highest peak in the middle of disease progression, is similar to the previous results of MCP-1 and sTREM2 studies $[55,56]$. Higher levels of inflammation have observed in earlier stages of the dementia, suggesting that inflammation precedes development of dementia. [55, 57]. Therefore, the likely reason for highest pattern is that EL levels may be relevant in inflammation. On the other hand, EL levels in the late $\mathrm{AD}$ stage might be an effect of drug treatment for conditions such as AD and other concomitant disorders such as hypercholesterolemia. Statins cause a decrease in the expression of EL as well as an increase in HDL-C [58, 59]. Additionally, because of the proinflammatory effect resulting in EL expression, anti inflammatory drugs may induce EL inactivation [60]. Most patients with $\mathrm{AD}$ have a comorbidity, which can include hypertension (20-30\%), being overweight or obese (20$40 \%)$, diabetes (20-25\%), hypercholesterolemia (>40\%), anemia (>20\%), or cerebrovascular damage (60\%) [61]; comorbidities require the administration of multiple drugs concurrently. This polypharmacy might lead to lower EL concentrations in patients with severe AD.

This study has some limitations. First, the average participant age was so high (average 75.8 years old) that even the NC group was likely to have slight cognitive loss. In fact, some participants felt subjective memory impairment. Indeed, there were no significant differences in CDR and CDR-SOB scores between the MCI (CDR $0.5 \pm 0.1$, CDR-SOB $1.5 \pm 1.1$ ) and NC (CDR $0.4 \pm 0.2$, CDR-SOB $0.7 \pm 0.4)$ groups, although the CDR and CDR-SOB scores were greater in patients with AD (CDR $1.5 \pm 0.8$, CDR-SOB $8.8 \pm 4.7$ ). This may have resulted in 
the absence of any significant differences in the mean EL concentrations between diagnostic groups. Second, this study did not completely exclude the effect of drugs on EL levels. When we adjusted for disease history, significance of the adjusted OR and 95\% CI of cognitive impairment in the upper EL range was maintained. Nonetheless, the information of disease history was derived from questionnaires and might lead to inaccuracies due to errors in subjective memory. Third, this was a single center study. Small and single center study may be in implicit bias regarding to ethnicity. The samples might not be representative, because we performed continuously rather than random sampling. Other center or multi-center validation studies are needed to address sampling errors and limitation of single center study. This was also a cross sectional study, and thus, the causal relationship between EL and cognitive impairment could not be determined. Further prospective and retrospective studies are required to assess the risk factors of EL on cognitive decline.

\section{Conclusions}

Despite evidence of HDL-C association with cognitive function and evidence of EL role as an HDL-C modulator, EL relevance in cognition was not studied. Here, we found to link plasma EL to cognitive impairment. We showed that plasma EL protein tends to increase with cognitive impairment, from cognitively normal to mild dementia cases. Elevated blood EL was associated with an increased risk of cognitive impairment. These results suggest that EL levels are likely to be relevant in the dementia when the process of change is underway rather than when the moderate damage has occurred. Further research should confirm the relevance between EL and cognition in a large population and in a prospective cohort for validation as cognition impairment and its progression biomarker.

\section{Additional file}

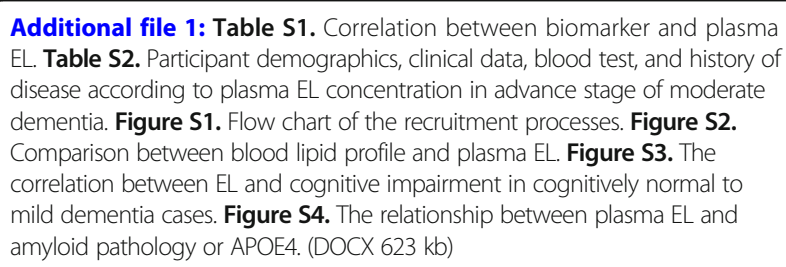

\section{Abbreviations}

AD: Alzheimer's Diseases; ANOVA: Analysis of variance analysis; ApoE: Apolipoprotein E; BMI: Body mass index; CDR: Clinical dementia rating; CDR-SOB: Clinical Dementia Rating Scale Sum of Boxes; EL: Endothelial lipase; Hb: Hemoglobin; HDL-C: High density lipoprotein cholesterol; LDL-C: Low-density lipoprotein cholesterol; MCl: Mild cognitive impairment; MMSE: Mini-mental state examination;
NC: Cognitively normal controls; OR: Odds ratio; RBC: Red blood cell; TC: Total cholesterol; TG: Triglyceride; WBC: White blood cell

\section{Acknowledgements}

We thank participants of the current study and contributors to clinic data collection and management.

\section{Authors' contributions}

SMY and JS contributed to the design of the study. SWS collected clinical data and plasma sample. JYP generated the plasma EL data and data analyses. SMY drafted the manuscript. All authors red and approved the final manuscript.

\section{Funding}

This research was supported by funds (2016-NG62001-00; 2016-ER6203-00; 2017-N162001-00) by Korea Centers for Disease Control and Prevention. The funding organization had no role in the design of the study and collection, analysis and interpretation of data and in writing the manuscript.

\section{Availability of data and materials}

The data analysed during this study are available from the corresponding author on reasonable request. They are also available on request from the national biobank of Korea.

Ethics approval and consent to participate

This study has been approved by institutional review boards from Samsung medical center, Korea. All written informed consents were obtained from patients and caregivers.

\section{Consent for publication}

Not applicable.

\section{Competing interests}

The authors declare that they have no competing interests.

\section{Author details}

'Division of Brain Diseases, Center for Biomedical Sciences, Korea National Institute of Health, Cheongju-si, Chungcheongbuk-do 28159, Republic of Korea. ${ }^{2}$ Department of Neurology, Samsung Medical Center, Sungkyunkwan University School of Medicine, Seoul 06351, Republic of Korea.

Received: 16 October 2018 Accepted: 5 June 2019

Published online: 19 June 2019

\section{References}

1. Foley P. Lipids in Alzheimer's disease: a century-old story. Biochim Biophys Acta. 2010;1801(8):750-3.

2. Bales KR. Brain lipid metabolism, apolipoprotein $E$ and the pathophysiology of Alzheimer's disease. Neuropharmacology. 2010;59(4-5):295-302.

3. Guerreiro R, Hardy J. Genetics of Alzheimer's disease. Neurotherapeutics. 2014;11(4):732-7.

4. International Genomics of Alzheimer's Disease C. Convergent genetic and expression data implicate immunity in Alzheimer's disease. Alzheimers Dement. 2015;11(6):658-71.

5. Pappolla MA, Bryant-Thomas TK, Herbert D, Pacheco J, Fabra Garcia M, Manjon M, Girones X, Henry TL, Matsubara E, Zambon D, et al. Mild hypercholesterolemia is an early risk factor for the development of Alzheimer amyloid pathology. Neurology. 2003;61(2):199-205.

6. Launer LJ, White LR, Petrovitch H, Ross GW, Curb JD. Cholesterol and neuropathologic markers of AD: a population-based autopsy study. Neurology. 2001;57(8):1447-52.

7. Matsuzaki T, Sasaki K, Hata J, Hirakawa Y, Fujimi K, Ninomiya T, Suzuki SO, Kanba S, Kiyohara Y, Iwaki T. Association of Alzheimer disease pathology with abnormal lipid metabolism: the Hisayama study. Neurology. 2011; 77(11):1068-75.

8. Anstey KJ, Ashby-Mitchell K, Peters R. Updating the evidence on the association between serum cholesterol and risk of late-life dementia: review and meta-analysis. J Alzheimers Dis. 2017;56(1):215-28.

9. Rasmussen KL, Tybjaerg-Hansen A, Nordestgaard BG, Frikke-Schmidt R. Plasma levels of apolipoprotein $\mathrm{E}$ and risk of dementia in the general population. Ann Neurol. 2015;77(2):301-11. 
10. Reitz C, Tang MX, Schupf N, Manly JJ, Mayeux R, Luchsinger JA. Association of higher levels of high-density lipoprotein cholesterol in elderly individuals and lower risk of late-onset Alzheimer disease. Arch Neurol. 2010;67(12): 1491-7.

11. Koch M, Jensen MK. HDL-cholesterol and apolipoproteins in relation to dementia. Curr Opin Lipidol. 2016;27(1):76-87.

12. Gatz M, Reynolds CA, Finkel D, Pedersen NL, Walters E. Dementia in Swedish twins: predicting incident cases. Behav Genet. 2010;40(6):768-75.

13. Mielke MM, Montine T, Khachaturian AS. Vascular diseases: one pathway toward new conceptual models of dementia. Alzheimers Dement. 2012;8(5 Suppl):S69-70

14. Miller WG, Myers GL, Sakurabayashi I, Bachmann LM, Caudill SP, Dziekonski A, Edwards S, Kimberly MM, Korzun WJ, Leary ET, et al. Seven direct methods for measuring HDL and LDL cholesterol compared with ultracentrifugation reference measurement procedures. Clin Chem. 2010; 56(6):977-86.

15. Contois JH, Warnick GR, Sniderman AD. Reliability of low-density lipoprotein cholesterol, non-high-density lipoprotein cholesterol, and apolipoprotein B measurement. J Clin Lipidol. 2011:5(4):264-72.

16. Cohen JC. Endothelial lipase: direct evidence for a role in HDL metabolism. J Clin Invest. 2003;111(3):318-21.

17. Ahmed W, Orasanu G, Nehra V, Asatryan L, Rader DJ, Ziouzenkova O, Plutzky J. High-density lipoprotein hydrolysis by endothelial lipase activates PPARalpha: a candidate mechanism for high-density lipoprotein-mediated repression of leukocyte adhesion. Circ Res. 2006;98(4):490-8.

18. Schmidt R, Schmidt H, Curb JD, Masaki K, White LR, Launer LJ. Early inflammation and dementia: a 25-year follow-up of the Honolulu-Asia aging study. Ann Neurol. 2002;52(2):168-74.

19. Jin W, Millar JS, Broedl U, Glick JM, Rader DJ. Inhibition of endothelial lipase causes increased HDL cholesterol levels in vivo. J Clin Invest. 2003;111(3): 357-62.

20. Ishida T, Choi S, Kundu RK, Hirata K, Rubin EM, Cooper AD, Quertermous T. Endothelial lipase is a major determinant of HDL level. J Clin Invest. 2003; 111(3):347-55

21. deLemos AS, Wolfe ML, Long CJ, Sivapackianathan R, Rader DJ. Identification of genetic variants in endothelial lipase in persons with elevated high-density lipoprotein cholesterol. Circulation. 2002;106(11): 1321-6.

22. Singaraja RR, Sivapalaratnam S, Hovingh K, Dube MP, Castro-Perez J, Collins HL, Adelman SJ, Riwanto M, Manz J, Hubbard B, et al. The impact of partial and complete loss-of-function mutations in endothelial lipase on highdensity lipoprotein levels and functionality in humans. Circ Cardiovasc Genet. 2013;6(1):54-62.

23. Ma K, Cilingiroglu M, Otvos JD, Ballantyne CM, Marian AJ, Chan L. Endothelial lipase is a major genetic determinant for high-density lipoprotein concentration, structure, and metabolism. Proc Natl Acad Sci U S A. 2003;100(5):2748-53.

24. Azumi H, Hirata K, Ishida T, Kojima Y, Rikitake Y, Takeuchi S, Inoue N, Kawashima S, Hayashi Y, Itoh H, et al. Immunohistochemical localization of endothelial cell-derived lipase in atherosclerotic human coronary arteries. Cardiovasc Res. 2003;58(3):647-54.

25. Yasuda T, Hirata K, Ishida T, Kojima Y, Tanaka H, Okada T, Quertermous T, Yokoyama M. Endothelial lipase is increased by inflammation and promotes LDL uptake in macrophages. J Atheroscler Thromb. 2007;14(4):192-201.

26. Kojma Y, Hirata K, Ishida T, Shimokawa Y, Inoue N, Kawashima S, Quertermous T, Yokoyama M. Endothelial lipase modulates monocyte adhesion to the vessel wall. A potential role in inflammation. J Biol Chem. 2004;279(52):54032-8.

27. Jin W, Sun GS, Marchadier D, Octtaviani E, Glick JM, Rader DJ. Endothelial cells secrete triglyceride lipase and phospholipase activities in response to cytokines as a result of endothelial lipase. Circ Res. 2003;92(6):644-50.

28. Petersen RC, Smith GE, Waring SC, Ivnik RJ, Tangalos EG, Kokmen E. Mild cognitive impairment: clinical characterization and outcome. Arch Neurol. 1999;56(3):303-8.

29. McKhann GM, Knopman DS, Chertkow H, Hyman BT, Jack CR Jr, Kawas CH, Klunk WE, Koroshetz WJ, Manly JJ, Mayeux R, et al. The diagnosis of dementia due to Alzheimer's disease: recommendations from the National Institute on Aging-Alzheimer's Association workgroups on diagnostic guidelines for Alzheimer's disease. Alzheimers Dement. 2011;7(3):263-9.

30. Ahn HJ, Chin J, Park A, Lee BH, Suh MK, Seo SW, Na DL. Seoul neuropsychological screening battery-dementia version (SNSB-D): a useful tool for assessing and monitoring cognitive impairments in dementia patients. J Korean Med Sci. 2010;25(7):1071-6.

31. Barthel H, Gertz HJ, Dresel S, Peters O, Bartenstein P, Buerger K, Hiemeyer F, Wittemer-Rump SM, Seibyl J, Reininger C, et al. Cerebral amyloid-beta PET with florbetaben (18F) in patients with Alzheimer's disease and healthy controls: a multicentre phase 2 diagnostic study. Lancet Neurol. 2011;10(5):424-35.

32. Kim HJ, Cho H, Werring DJ, Jang YK, Kim YJ, Lee JS, Lee J, Jun S, Park S, Ryu $\mathrm{YH}$, et al. 18F-AV-1451 PET imaging in three patients with probable cerebral amyloid Angiopathy. J Alzheimers Dis. 2017;57(3):711-6.

33. Farrar G. Regional visual read inspection of [18F] flutemetamol brain images from end-of-life and amnestic MCl subjects. J Nuclear Med. 2017:58:1250.

34. Badellino KO, Wolfe ML, Reilly MP, Rader DJ. Endothelial lipase concentrations are increased in metabolic syndrome and associated with coronary atherosclerosis. PLoS Med. 2006;3(2):e22.

35. Stephan BC, Hunter S, Harris D, Llewellyn DJ, Siervo M, Matthews FE, Brayne C. The neuropathological profile of mild cognitive impairment (MCI): a systematic review. Mol Psychiatry. 2012;17(11):1056-76.

36. Amin N, Jovanova O, Adams HH, Dehghan A, Kavousi M, Vernooij MW, Peeters RP, de Vrij FM, van der Lee SJ, van Rooij JG, et al. Exomesequencing in a large population-based study reveals a rare Asn396Ser variant in the LIPG gene associated with depressive symptoms. Mol Psychiatry. 2017;22(4):537-43.

37. van den Kommer TN, Dik MG, Comijs HC, Jonker C, Deeg DJ. Role of lipoproteins and inflammation in cognitive decline: do they interact? Neurobiol Aging. 2012;33(1):196 e191-12.

38. Singh-Manoux A, Gimeno D, Kivimaki M, Brunner E, Marmot MG. Low HDL cholesterol is a risk factor for deficit and decline in memory in midlife: the Whitehall II study. Arterioscler Thromb Vasc Biol. 2008;28(8):1556-62.

39. Song F, Poljak A, Crawford J, Kochan NA, Wen W, Cameron B, Lux O, Brodaty H, Mather K, Smythe GA, et al. Plasma apolipoprotein levels are associated with cognitive status and decline in a community cohort of older individuals. PLoS One. 2012;7(6):e34078.

40. Heppner FL, Ransohoff RM, Becher B. Immune attack: the role of inflammation in Alzheimer disease. Nat Rev Neurosci. 2015;16(6):358-72.

41. van Dijk G, van Heijningen S, Reijne AC, Nyakas C, van der Zee EA, Eisel UL. Integrative neurobiology of metabolic diseases, neuroinflammation, and neurodegeneration. Front Neurosci. 2015;9:173.

42. Sardi F, Fassina L, Venturini L, Inguscio M, Guerriero F, Rolfo E, Ricevuti G. Alzheimer's disease, autoimmunity and inflammation. The good, the bad and the ugly. Autoimmun Rev. 2011;11(2):149-53.

43. Takeda S, Sato N, Morishita R. Systemic inflammation, blood-brain barrier vulnerability and cognitive/non-cognitive symptoms in Alzheimer disease: relevance to pathogenesis and therapy. Front Aging Neurosci. 2014;6:171.

44. Eikelenboom P, Hoozemans JJ, Veerhuis R, van Exel E, Rozemuller AJ, van Gool WA. Whether, when and how chronic inflammation increases the risk of developing late-onset Alzheimer's disease. Alzheimers Res Ther. 2012;4(3):15

45. Alonso R, Pisa D, Marina Al, Morato E, Rabano A, Carrasco L. Fungal infection in patients with Alzheimer's disease. J Alzheimers Dis. 2014;41(1): 301-11.

46. Pisa D, Alonso R, Rabano A, Rodal I, Carrasco L. Different brain regions are infected with Fungi in Alzheimer's disease. Sci Rep. 2015;5:15015.

47. Maheshwari P, Eslick GD. Bacterial infection and Alzheimer's disease: a metaanalysis. J Alzheimers Dis. 2015;43(3):957-66.

48. Eimer WA, Vijaya Kumar DK, Navalpur Shanmugam NK, Rodriguez AS, Mitchell T, Washicosky KJ, Gyorgy B, Breakefield XO, Tanzi RE, Moir RD. Alzheimer's disease-associated beta-amyloid is rapidly seeded by Herpesviridae to protect against brain infection. Neuron. 2018;99(1):56-63 e53.

49. Harris SA, Harris EA. Herpes simplex virus type 1 and other pathogens are key causative factors in sporadic Alzheimer's disease. J Alzheimers Dis. 2015; 48(2):319-53.

50. Al-Rasheed A. Elevation of white blood cells and platelet counts in patients having chronic periodontitis. Saudi Dental J. 2012;24(1):17-21.

51. Jesri A, Okonofua EC, Egan BM. Platelet and white blood cell counts are elevated in patients with the metabolic syndrome. J Clin Hypertens. 2005; 7(12):705-11 quiz 712-703.

52. Badellino KO, Wolfe ML, Reilly MP, Rader DJ. Endothelial lipase is increased in vivo by inflammation in humans. Circulation. 2008;117(5):678-85.

53. Paradis ME, Badellino KO, Rader DJ, Deshaies Y, Couture P, Archer WR, Bergeron N, Lamarche B. Endothelial lipase is associated with inflammation in humans. J Lipid Res. 2006;47(12):2808-13. 
54. Shiu SW, Tan KC, Huang Y, Wong Y. Type 2 diabetes mellitus and endothelial lipase. Atherosclerosis. 2008;198(2):441-7.

55. Galimberti D, Fenoglio C, Lovati C, Venturelli E, Guidi I, Corra B, Scalabrini D, Clerici F, Mariani C, Bresolin N, et al. Serum MCP-1 levels are increased in mild cognitive impairment and mild Alzheimer's disease. Neurobiol Aging. 2006;27(12):1763-8.

56. Suarez-Calvet M, Kleinberger G, Araque Caballero MA, Brendel M, Rominger A, Alcolea D, Fortea J, Lleo A, Blesa R, Gispert JD, et al. sTREM2 cerebrospinal fluid levels are a potential biomarker for microglia activity in early-stage Alzheimer's disease and associate with neuronal injury markers. EMBO molecular medicine. 2016;8(5):466-76.

57. Tarkowski E, Andreasen N, Tarkowski A, Blennow K. Intrathecal inflammation precedes development of Alzheimer's disease. J Neurol Neurosurg Psychiatry. 2003;74(9):1200-5.

58. Qiu G, Hill JS. Atorvastatin decreases lipoprotein lipase and endothelial lipase expression in human THP-1 macrophages. J Lipid Res. 2007;48(10): 2112-22.

59. Kojima Y, Ishida T, Sun L, Yasuda T, Toh R, Rikitake Y, Fukuda A, Kume N, Koshiyama $\mathrm{H}$, Taniguchi A, et al. Pitavastatin decreases the expression of endothelial lipase both in vitro and in vivo. Cardiovasc Res. 2010; 87(2):385-93.

60. Yu JE, Han SY, Wolfson B, Zhou Q. The role of endothelial lipase in lipid metabolism, inflammation, and cancer. Histol Histopathol. 2018;33(1):1-10.

61. Cacabelos R, Meyyazhagan A, Carril JC, Cacabelos P, Teijido O.

Pharmacogenetics of vascular risk factors in Alzheimer's disease. Journal of personalized medicine. 2018;8(1).

\section{Publisher's Note}

Springer Nature remains neutral with regard to jurisdictional claims in published maps and institutional affiliations.

Ready to submit your research? Choose BMC and benefit from:

- fast, convenient online submission

- thorough peer review by experienced researchers in your field

- rapid publication on acceptance

- support for research data, including large and complex data types

- gold Open Access which fosters wider collaboration and increased citations

- maximum visibility for your research: over $100 \mathrm{M}$ website views per year

At BMC, research is always in progress.

Learn more biomedcentral.com/submissions 